\title{
CLINICAL AND IMMUNOHISTOCHEMICAL FEATURES OF PRIMARY BREAST CANCER AND METACHRONOUS OVARIAN AND ENDOMETRIAL TUMORS
}

\author{
A.E. Kryzhanivska, I.B. Dyakiv*, I. Kyshakevych \\ Ivano-Frankivsk National Medical University, Ivano-Frankivsk 76018, Ukraine
}

\begin{abstract}
The aim of the study was to assess the patterns of development of metachronous cancer (endometrial cancer, EC, and ovarian cancer, $\mathrm{OC}$ ) in breast cancer (BC) patients dependent of receptor phenotype of breast tumors. Materials and Methods: In the study, 63 patients with BC, who developed metachronous EC $(n=47)$ or OC $(n=16)$ were enrolled. Expression of estrogen receptor (ER), progesterone receptor (PR), HER/2neu was assessed using immunohistochemical approach. Results: $\mathrm{BC}$ in patients with metachronous EC and $\mathrm{OC}$ was characterized by a different frequency of molecular subtypes with the dominance of luminal A (36\%) and B (43\%) subtypes. In primary BC, we have established a correlation between ER expression and regional lymph nodes status $(r=-0.50, p<0.05)$; negative correlation between HER2/neu expression and tumor stage $(r=-0.48, p<0.05)$; between the molecular subtype of $\mathrm{BC}$ and its size $(r=-0.33, p<0.05)$, the molecular subtype of primary $\mathrm{BC}$ and metastases in regional lymph nodes $(r=0.27, p<0.05)$. In the patients with luminal subtype $\mathrm{BC}$ metachronous tumors developed with the highest frequency $(\mathrm{OC}-\mathbf{5 0 \%}, \mathrm{EC}-\mathbf{5 0 \%})$. After treatment of primary $\mathrm{BC}$ metachronous tumors developed at different period: EC $(22.2 \%)$ - most often in 3-5 years, OC (11.0\%) - after 10 years and more. Conclusion: Our data evidence on the clinical significance of the individual characteristics of the BC, especially its molecular subtype, and the need to calculate the personalized risk of development of metachronous tumors of the reproductive system in patients with the BC.
\end{abstract}

Key Words: breast cancer, metachronous endometrial cancer, metachronous ovarian cancer, hormonal receptors, HER2/neu, immunohistochemistry.

Over recent years, breast cancer $(\mathrm{BC})$ has remained the most common malignant disease among women both in Ukraine and in most countries of Western Europe and America. Analyzing the survival rates of patients with $B C$ in recent decades, one may conclude that improvement of $B C$ treatment results is achieved. According to Surveillance, Epidemiology and End Results data, the statistical database of the National Cancer Institute in the USA, 5-year survival constitutes $83.4-98.4 \%$ in case of localized forms of BC and $23.3 \%$ in case of metastatic BC. Such results have been achieved due to a personified approach to $\mathrm{BC}$ treatment [4].

The emergence of metachronous tumors, namely $\mathrm{BC}$, endometrial cancer (EC) and ovarian cancer $(\mathrm{OC})$, has become particularly relevant over the last decade. Numerous studies have shown that BC is a hormonedependent cancer associated with a chronic effect of estrogens related to an impaired estrogen-progesterone balance. According to the estrogen theory, estrogens and their receptors play an essential role in the initiation and promotion of the process of malignant transformation, since hyperestrogenism is one of the factors modulating genes expression leading to dysregulation of cellular signaling and the development of metachronous BC [1-4].

$A$ well-known fact is that $B C$ represents a heterogeneous tumor group. According to the molecular genetic classification, four subtypes of BC are dis-

Submitted: December 5, 2017.

*Correspondence: E-mail: irynadjakiv@ukr.net

Abbreviations used: $\mathrm{BC}$ - breast cancer; $\mathrm{EC}$ - endometrial can-

cer; ER - estrogen receptor; OC - ovarian cancer; PR - proges-

terone receptor; RLN - regional lymph nodes. tinguished: luminal A, luminal B, HER-2/neu positive, basal or triple-negative. According to modern studies, the presence of steroid hormones receptors is an important biological feature of malignant tumors and can determine the course of the disease. In addition, the disruption of hormonal balance in the body of women is also associated with the $\mathrm{EC}$ and $\mathrm{OC}$ onset. Clinical course of hormone related tumors depends on decrease or loss of expression of both progesterone receptors (PR) and estrogen receptors (ER), which manifests itself in a greater aggressiveness of the tumor process: more invasion, metastasis and unfavorable course of disease [5-7]. But at present time, no clear relation between the clinical-biological features of $B C$ receptor phenotype and the development of subsequent metachronous hormone related cancers has been established. The above mentioned data suggest the expediency of studying the ER, PR and HER-2/neu status in patients with primary BC tumors and metachronous $\mathrm{OC}$ and $\mathrm{EC}$. This will allow to assess the receptor status in these neoplasms and evaluate its significance in the course of the tumor disease.

\section{MATERIALS AND METHODS}

In the study, 63 patients with BC, in which, after the completion of treatment, another oncological disease has developed, were enrolled: EC developed in 47 patients, OC - in 16 patients. The study did not include $B C$ patients with $B C$ progression or metastasis. The verification of $\mathrm{BC}$ and the second oncological disease was carried out by histological examination of the biopsy and/or surgical material of biological specimens. The clinical diagnostics of $\mathrm{BC}$ was performed according to the TNM clas- 
sification (2002) and the diagnostics of second oncological disease was carried out by histological examination (World Health Organization, 2003) of the biopsy and/or surgical material of biological specimens.

The patients received combined treatment: surgical, chemotherapeutic, radiological, hormonal therapy (if necessary). $86 \%$ of patients received hormone therapy with tamoxifen $(20 \mathrm{mg}$ once a day for 5 years). All patients were cured at the Communal Institution "Precarpathian Clinical Cancer Center" from 1986 to 2016, treatment, according to the order of the Ministry of Health of Ukraine No. 396 "On Approval and Implementation of Medical-Technological Documents for the Standardization of Medical Assistance of Cancer Patients". The study was approved by the Ethics Commission of Ivano-Frankivsk National Medical University (conclusion No. 83).

To assess ER, PR and HER2/neu expression in the samples of $\mathrm{BC}, \mathrm{EC}$ and $\mathrm{OC}, 4 \mu \mathrm{m}$ histologic slides were prepared from paraffin blocks of tumors. Immunohistochemical study was performed using the following monoclonal antibodies: antiER - clone 1D5, antiPR - clone PgR636, antiHER/2neu - clone c-erbB-2 (Dako Cytomation, Denmark). The degree of immunohistochemical reaction was assessed as «+++» - strong, «++» - moderate, «+» - low or no expression (0). The number of cells with $>10 \%$ with a strong and moderate expression was considered as positive expression of the examined markers.

The statistical analysis of the data was performed using Microsoft ${ }^{\oplus}$ Office Exce ${ }^{\circledast} 2007$ and Statistica v.6.1 (Statsoft Inc., USA) programs for variation statistics, correlation, regression, multiple correlation-regression analysis. Changes were considered to be significant at $p<0.05$.

\section{RESULTS AND DISCUSSION}

The conducted research is based on the results of clinical and immunohistochemical investigation of 63 patients with BC, in which after the completion of treatment, another oncological disease was arized (EC or $O C$ ). The age of $B C$ patients varied from 25 to 83 years (at average $53.9 \pm 11.8$ years) (Table 1). BC cases were assessed according to the TNM classification (2002) (Table 2), and BC was mostly of stages I and II (27.0 and $50.8 \%$, respectively), and stage III (19.0\%). All 63 patients with $B C$ were operated because of the second oncological disease: EC developed in 47 patients, $\mathrm{OC}-$ in 16 patients.

Table 1. Distribution of patients with primary $B C$ by age

\begin{tabular}{|c|c|c|}
\hline Age, years & $n=63$ & $100 \%$ \\
\hline 25 & 1 & 1.6 \\
\hline $30-39$ & 6 & 9.5 \\
\hline $40-49$ & 12 & 19.0 \\
\hline $50-59$ & 18 & 28.6 \\
\hline $60-69$ & 15 & 23.8 \\
\hline $70-79$ & 9 & 14.3 \\
\hline $80-83$ & 2 & 3.3 \\
\hline Total & 63 & 100.0 \\
\hline Average age & \multicolumn{2}{|c|}{$53.9 \pm 11.8$} \\
\hline
\end{tabular}

Table 2. Distribution of patients with primary BC according to TNM classification (2002)

\begin{tabular}{lcc}
\hline \multicolumn{1}{c}{ Stage of primary BC } & $\mathrm{n}$ & $\%$ \\
\hline I stage: T1N0M0 & 17 & 27.0 \\
II stage: T0-3N0-1M0 & 32 & 50.8 \\
III stage: T0-4N0-3M0 & 12 & 19.0 \\
IV stage: T0-4N0-3M1 & 2 & 3.2 \\
Total & 63 & 100.0 \\
\hline
\end{tabular}

All patients underwent surgical treatment. Mastectomy by Madden was performed in 36 (57.2\%) patients with BC, mastectomies by Halstead - in $14(22.2 \%)$, and by Petit - in 9 (14.3\%). Organ-preserving operation (quadrantectomy) was done in $4(6.3 \%)$ patients (Table 3).

Table 3. Distribution of patients with primary BC according to surgical treatment

\begin{tabular}{lcc}
\hline \multicolumn{1}{c}{ Surgical trearment } & $\mathrm{n}$ & $\%$ \\
\hline Quadrantectomy & 4 & 6.3 \\
Mastectomy by Maden & 36 & 57.2 \\
Mastectomy by Petit & 9 & 14.3 \\
Mastectomy by Halsted & 14 & 22.2 \\
Total & 63 & 100.0 \\
\hline
\end{tabular}

After surgical treatment $86 \%$ of patients received hormone therapy (tamoxifen $20 \mathrm{mg}$ once a day for 5 years). Metachronous EC occurred mainly in the period from 3 to 5 years after the treatment of $B C$ ( 14 patients $(22.2 \%)$ ), and metacharonic OC - in period longer than 10 years (in 7 patients (11.0\%)) (Table 4).

Table 4. Period of development of metachronous EC and OC

\begin{tabular}{|c|c|c|}
\hline \multicolumn{3}{|c|}{$\begin{array}{l}\text { Cases of development of metachronous tumors after treatment } \\
\text { of primary BC }(n=63 / 100 \%)\end{array}$} \\
\hline Terms after treatment & $\mathrm{EC}, \mathrm{n}(\%)$ & $\mathrm{OC}, \mathrm{n}(\%)$ \\
\hline of $B C$ & $47(74.6)$ & $16(25.4)$ \\
\hline Up to 1 year & $6(9.5)$ & $\frac{(20.4)}{1(1.6)}$ \\
\hline From 1 to 3 years & $5(7.9)$ & $2(3.2)$ \\
\hline From 3 to 5 years & $14(22.2)$ & $3(4.8)$ \\
\hline From 5 to 10 years & $10(15.9)$ & $3(4.8)$ \\
\hline More than 10 years & 12 (19.1) & $7(11.0)$ \\
\hline
\end{tabular}

The stage of the metachronous tumors was the following: EC was of stage I in $34(54.0 \%)$ cases, stages II and III - in $9(14.3 \%)$ and $4(6.3 \%)$ cases, respectively; OC - of stage III in $8(12.7 \%)$ cases, stage II in $5(7.9 \%)$ cases, and stage I - in $3(4.8 \%)$ patients.

According to the immunohistochemical features, the breast tumors were of 4 molecular subtypes: luminal A subtype constituting $36 \%$; luminal B subtype with the highest frequency constituting 43\%; Her2/ neu-positive subtype $-7 \%$; and basal-like subtype (or triple-negative subtype, ER-PR-Her2/neu-) $14 \%$ cases (Table 5 ). In the patients with luminal subtype $\mathrm{BC}$ metachronous tumors developed with the highest frequency $(\mathrm{OC}-50 \%$, EC $-50 \%)$.

One of the most important clinical characteristics is the presence of metastases in RLN or organs distant from the tumor. In the majority of patients with $B C$ they were absent regardless of the tumor molecular subtype: luminal A $-67.9 \%$, luminal B $-68.6 \%$, triple negative $-85.7 \%$.

Statistical analysis of the data showed that there is a significant correlation between ER expression and RLN status $(r=-0.50, p<0.05)$; expression of HER2/neu and the stage of the disease $(r=-0.48$, $p<0.05)$. The relation between the molecular subtype of the primary BC with its size $(r=-0.33, p<0.05)$ and 
Table 5. The frequency of molecular subtypes of primary tumors and metachronous cancer and correlation between $\mathrm{BC}$ indexes

\begin{tabular}{|c|c|c|c|c|}
\hline \multirow[b]{2}{*}{ Patients (n/\%) } & \multicolumn{4}{|c|}{ Molecular subtype, $n=63$} \\
\hline & $\begin{array}{c}\text { Luminal A } \\
\text { ER+PR+ } \\
\text { Her2/neu+, } \\
\%\end{array}$ & $\begin{array}{c}\text { Luminal B } \\
\text { ER+PR+, } \\
\text { Her2/neu-, } \\
\%\end{array}$ & $\begin{array}{c}\text { Her2/neu- } \\
\text { positive } \\
\text { ER+PR+, } \\
\text { Her2/neu+, } \\
\%\end{array}$ & $\begin{array}{c}\text { Triple-nega- } \\
\text { tive subtype } \\
\text { ER-, PR-, } \\
\text { Her2/neu-, } \\
\%\end{array}$ \\
\hline $\begin{array}{l}\text { Prim } \\
63 / 1\end{array}$ & 36 & 43 & 10 & 10 \\
\hline $\begin{array}{l}47 / 10 \\
\text { Meta }\end{array}$ & 33 & 50 & 10 & 7 \\
\hline \multicolumn{5}{|c|}{$\begin{array}{ccc}20 & 50 & 12 \\
\text { Correlation between } \mathrm{BC} \text { indexes }\end{array}$} \\
\hline \multicolumn{5}{|c|}{$\begin{array}{l}\text { ER expression and regional lymph nodes (RLN) status }(r=-0.50, p<0.05) \\
\text { HER2/neu expression and stage }(r=-0.48, p<0.05) \\
\text { Molecular subtype of the primary BC and its size }(r=-0.33, p<0.05) \\
\text { Molecular subtype of the primary BC and metastases in RLN } \\
(r=0.27, p<0.05)\end{array}$} \\
\hline
\end{tabular}

the presence of metastases in $\operatorname{RLN}(r=0.27, p<0.05)$ were also found.

It seemed appropriate to analyze further the relation between ER, PR and HER2/neu expression in these patients with the clinical and pathological features of tumor growth which are important for the estimation of the disease prognosis: stage, tumor size, metastases of RLN, BC molecular subtype.

The largest number of ER+ and HER2/neu-positive tumors was detected in patients with stage I ( $100 \%$ and $100 \%$, respectively) of both $\mathrm{BC}$ and $\mathrm{EC}$ in comparison with stages II and III of BC and EC ( 83 and $54 \%$, respectively); in patients with BC and EC of stage II or III 67 and 33\%, respectively. The significant difference in PR expression depending on the stage of the tumor process was not detected. The statistical analysis of the data indicated the existence of an inverse relationship between ER, Her2/neu expression and the disease stage. Positive expression of steroid hormone receptors was detected in 12 and $50 \%$ of patients with stages II and III of metachronous OC.

Recurrence-free and overall survival is in reverse correlation with RLN metastases [7-11]. Taking this into consideration, we conducted a research on the relation between the receptor status of $\mathrm{BC}, \mathrm{EC}$ and OC tumor cells and metastasis. ER expression (100\% of tumor tissue samples) was observed in patients without metastases in RLN. HER2/neu expression was noted in somewhat lower number of cases (83\%). Even less number of studied tumors samples (67\%) were PR positive.

In case of RLN metastases, different frequency of expression of steroid hormone receptors in the primary tumors was noted. Namely, ER and PR expression was detected in $75 \%$ of cases in the group of patients with RLN N1 status. This was higher in comparison with patients with RLN N3 (50\%). The statistical analysis showed the existence of an inverse correlation between RLN status and ER, PR and HER2/neu expression in a primary tumor.

The relation between the receptors expression (ER, $\mathrm{PR}$ ) and HER2/neu and the age of patients in case of secondary oncology onset was also analyzed. In particular, the age of patients with positive recep- tor status (ER+PR+HER2/neu+) was higher in case of secondary oncology disease onset in comparison with the absence of expression of these molecules.

Thus, secondary cancer occurred at the age of 63.9 years in patients with ER-positive BC. This was about 6 years higher on average compared to a group of patients ( 57.5 years) with ER-negative primary tumors. The same regularity was noted in patients with PR and HER-positive BC. It should be noted that the development of metachronous cancer occurred 10 years later in patients with HER2/neu-positive $\mathrm{BC}$ in comparison with patients with HER2/neu-negative BC (Table 6).

Table 6. Expression of immunohistochemical markers in tumor tissue of primary $\mathrm{BC}$ and average age of development of metachronous $\mathrm{EC}$ or $\mathrm{OC}$

\begin{tabular}{lcc}
\hline \multirow{2}{*}{ Markers } & \multicolumn{1}{c}{ Positive expression of markers } & Negative expression \\
\cline { 2 - 3 } \multicolumn{1}{c}{ Average age of patients, years } \\
\hline $\mathrm{RE}$ & $63.9 \pm 1.2$ & $57.5 \pm 1.0$ \\
$\mathrm{RP}$ & $64.2 \pm 4.1$ & $60.2 \pm 3.5$ \\
$\mathrm{HER} 2 /$ neu & $67.3 \pm 2.2$ & $57.9 \pm 2.7$ \\
\hline
\end{tabular}

The statistical analysis of the data indicated the correlation between ER expression and the stage of the tumor process, RLN status, HER2/neu expression and RLN status in BC patients. The relation between the molecular subtype of BC and metastasis in RLN was also detected.

\section{CONCLUSION}

The $\mathrm{BC}$ cases with metachronous $\mathrm{EC}$ and $\mathrm{OC}$ are characterized by a different frequency of BC molecular subtypes with the dominance of luminal A (36\%) and B (43\%) subtypes. Statistical analysis of the obtained results revealed correlation between the different clinical characteristics of the $\mathrm{BC}$. In the primary $B C$, we have established a correlation between ER expression and RLN status $(r=-0.50, p<0.05)$; negative correlation between HER2 / neu expression and stage $(r=-0.48, p<0.05)$; between the molecular subtype of BC and its size $(r=-0.33, p<0.05)$, the molecular subtype of primary $\mathrm{BC}$ and metastases in RLN ( $r=0.27, p<0.05)$. The highest frequency of metastases is noted in patients with triple negative BC. In the patients with luminal subtype BC metachronous tumors developed with the highest frequency. Metachronous tumors developed at different period after treatment of primary tumors: EC (22.2\%) most often in 3-5 years, OS (11\%) - most often after 10 years or more. Our data evidence on the clinical significance of the individual characteristics of the $B C$, especially its molecular subtype and the need to calculate the personalized risk of development of metachronous tumors of the reproductive system in patients with the BC.

\section{REFERENCES}

1. Cancer in Ukraine, 2013-2014. Incidence, mortality, indicators, of the oncological service. Bull Nat Cancer Registry of Ukraine 2015; (16): 106.

2. Bolton JL, Thatcher GR. Potential mechanisms of estrogen quinone carcinogenesis. Chem Res Toxicol 2008; 21: $93-101$. 
3. Rizner TL. Estrogen biosynthesis, phase I and phase II metabolism, and action in endometrial cancer. Mol Cell Endocrinol 2013; 381: 124-39.

4. Tashiro H, Katabuchi H. The relationship between estrogen and genes in the molecular pathogenesis of endometrial cancer. Curr Obstet Gynecol Rep 2014; 3: 9-17.

5. Buchynska LG, Iurchenko NP, Grinkevych VN, et al. Expression of the estrogen and progesterone receptors as prognostic factor in serous ovarian cancers. Exp Oncol 2009; 31: 48-51.

6. Jarzabek K, Koda M, Walentowicz-Sadlecka M, et al. Altered expression of ERs, aromatase, and COX2 connected to estrogen action in type 1 endometrial cancer biology. Tumor Biol 2013; 34: 4007-16.
7. Fehm T, Maul H, Gebauer S, et al. Prediction of axillary lymph node status of breast cancer patients by tumorbiological factors of the primary tumor. Strahlenther Onkol 2005; 181: 580-6.

8. Fitzgibbons PL, Page DL, Weaver D, Thor AD. Prognostic factors in breast cancer. College of American Pathologists Consensus Statement, 1999. Arch Pathol Lab Med 2000; 124: $966-78$

9. Karanikolic A, Djordjevic N, Pesic M. Breast cancer in elderly women. Arch Gerontol Geriatr 2004; 39: 291-9.

10. Pappo I, Karni T, Sandbank J, et al. Breast cancer in the elderly: histological, hormonal and surgical characteristics. Oncologist 2011; 16: 61-70.

11. Kaunitz AM. Breast cancer after age 80: diagnosis, treatment and outcomes. Int J Breast Cancer 2011; 6: 34-40. 